\title{
EXPLORING LOW AND HIGH STUDENTS' PERCEPTION ON ENGAGING E-DICTIONARY IN MASTERING VOCABULARY: CROSS-SECTIONAL SURVEY
}

\author{
Gilang Nugraha \\ English Department Program, Faculty of Teacher Training and Education \\ Galuh University Ciamis, Indonesia \\ E-mail: gilangnugrah24@gmail.com \\ Ratnawati \\ English Department Program, Faculty of Teacher Training and Education \\ Galuh University Ciamis, Indonesia \\ E-mail: ratnawatienglisheducation@yahoo.com \\ AM. Surachmat \\ English Department Program, Faculty of Teacher Training and Education \\ Galuh University Ciamis, Indonesia \\ E-mail: surachmat08@gmail.com
}

\begin{abstract}
APA Citation: Nugraha, G., Ratnawati, \& Surachmat, AM. (2018). Exploring low and high students' perception on engaging e-dictionary in mastering vocabulary: Cross-sectional survey. Indonesian EFL Journal, 5(1), 37-44. doi: 10.25134/ieflj.v5i1.1609.
\end{abstract}

Received: 24-09-2018

Accepted: 26-11-2018

Published: 01-01-2019

\begin{abstract}
This paper is a survey study that aims at investigating low and high achievement students' perception on engaging electronic dictionary in enhancing their vocabulary mastery. There were 30 students involved in this study consisting of 16 students as the high achievement students and 14 students as the low achievement students. They were considered as high and low students based on the result of their last examination score. Questionnaire and interview were used to collect the data. The results of the study showed that low achievement students have positive perception on the use of electronic dictionary especially Google Translate. Most of them agreed that the use of Google Translate helped them in improving their English vocabulary mastery because Google Translate is easy to use and fast in translating meaning of words. Moreover, most of the high achievement students also have positive perception on the use of Google Translate because it is easy to use and free, it can be accessed by using their smartphones. Nevertheless, the problems also found in the use of electronic dictionary especially Google Translate, including bad internet connection which affected the performance of Google Translate. It can be conluded that there are almost similar perception between low and high achievement students on the use of electronic dictionary especially Google Translate.
\end{abstract}

Keywords: electronic dictionary; google translate; low and high achievement students; perception; vocabulary mastery.

\section{INTRODUCTION}

In recent years, technology has been used to both assist and enhance language learning. Teachers have incorporated various forms of technology to support their teaching and learning process. Technology Enhanced Language Learning (TELL) deals with the impact of technology on teaching and learning a foreign language. It provides a lot more flexibility and more learning styles of the learners, it can be used alongside textbooks for much more in depth learning experience, it turns the classroom into a student centred environment, and it improves motivation and develops better attitudes in students towards learning. Technology continues to grow in importance 
as a tool to assist teachers of foreign languages in facilitating and mediating language learning for their students (Boonyopakorn, 2016).

Nowdays, technological developments with the adoption of mobile devices and applications have translated into huge opportunities for English as a foreign language (EFL) especially in students' vocabulary mastery. As a matter of fact, mobile language learning without no doubt plays an important role in enhancing students' skills (Thornton \& Houser, 2005). Learning vocabularies via mobile device has become one of the useful ways. The emergence of new technologies, especially the internet, has resulted in a major transition in terms of business, education, science, and technological progress, all of which demand high proficiency in English. Besides, the implementation of the 2013 curriculum of the 21 st century in several schools requires teachers to follow the development of technology in teaching and learning process.

Electronic dictionary has become an important instrument for learning a language, especially for learning English vocabulary. The searching process for a word in an electronic dictionary is greatly shortened by the mobile device advantage of speed. It is better than paper dictionary which takes longer time in searching a word. Looking up a word in a paper dictionary is a process of switches, first switching from a reading material to dictionary and then from the dictionary to the reading material. It is a disruptive process. Now, with the help of electronic dictionaries, learners' thought flow is no longer disrupted as much as before, especially with the function of instantly obtaining the explanation of a word. According to Amiran and Heshmatifar (2013, p. 36-37), an electronic dictionary is "an electronic aid that offers immediate access to reference information with a clear and direct return path to the target information". Electronic dictionary can potentially contribute to language learning and instruction. Over and above the fact, electronic dictionaries play a significant role in vocabulary learning.

Vocabulary is an important thing to be mastered by the students in learning a foreign language, because it is a foundation for other language components such as pronunciation, spelling, meaning, and grammar. Thornbury (2002, p. 16) stated that without grammar very little can be conveyed, without vocabulary nothing can be conveyed. In other words, the first thing that has to be mastered by language learners in learning a language is vocabulary. In addition, students' vocabulary mastery academically is needed in language learning, because it is essential to be successfully in reading, listening, speaking and writing.

Furthermore, Cameron (2001, p. 72) believes that building a useful vocabulary is central to the learning of a foreign language at primary level. Building vocabulary means both understanding the meanings of words and learning to decode those words. The larger the students master vocabulary, the better they perform their language. By having limited vocabulary, the students will find difficulties in mastering reading and other skills. The success of the learner in learning a language depends on not only the size of vocabulary but also vocabulary building.

Moreover, Robbins and Judge (2013, p. 166) state that perception is a process by which individuals organize and interpret their sensory impressions in order to give meaning to their environment. Perception can also be seen as a cognitive process that enables us to interpret and understand our surroundings. In other words, perception basically refers to the manner in which people organize, interpret and experience ideas and use stimulus materials in the environment so that they satisfy their needs.

This study is underpinned by some previous studies. The first previous study is conducted by Murnani and Salehi (2015). The study focused on investigating the impacts of using an electronic dictionary in learning a second language collocation. The second previous study is conducted by 
Rezaei and Davoudi (2016). This study focused on investigating the influence of Electronic Dictionaries and Paper Dictionaries on vocabulary learning and retention of Iranian EFL learners. Then, the third previous study is conducted by Grami and Hashemian (2017). The purpose of this study was to investigate the effects of paper and electronic dictionaries on Iranian intermediate learners' reading comprehension.

Unfortunately, research on investigating the perception onn the use of electronic dictionary is rarely found. Therefore, this present study attemps to fill the gap by conducting research on investigating students' perceptions on the use of electronic dictionary. It aims to understand whether they are interested in using electronic dictionary or not. Here, the writers focus on investigating students' perception especially low and high achievement students' perception on the use of electronic dictionary, especially the use of Google Translate, in enhancing their vocabulary mastery. Besides, the writers also attempt to identify problems that are commonly faced while using electronic dictionary.

\section{METHOD}

This study was conducted in survey study approach. According to Fink (2002, p. 1), survey is a system for collecting information from or about people to describe, compare, or explain their knowledge, attitudes, and behavior. The writer applied cross-sectional survey because the information is collected at one point in time (Creswell, 2012, p. 377).

This study involved 30 students of the tenth grade consisting of 16 high achievement students and 14 low achievement students. Of the 30 students, 6 students involved in interview session, consisting of 3 students as the high achievement students and 3 students as the low achievement students. The students' level of achievement was determined based on their last examination marks. Students who got mark higher than classroom average marks in the last examination were taken as high achievement students and those who got mark lower than classroom average marks were taken as low achievement students.

The writer chose one of prestigious senior high school in Ciamis as the place of the research for some reasons. First, this school is allowed the students to use electronic dictionaries in mobile phone as a tool of learning. Second, there is free Wi-Fi in this school that allows students to access the internet freely, so they can access sites that can help them in learning process. In conducting the study, the writers used two instruments as data collecting technique, namely questionnaire and interview. According to Creswell (2012, p. 382), "Questionnaire is a form used in a survey design that population in a study complete and return to the researcher". In this study, the writer gave a closed-ended questionnaire in Likert scale to the students. The closedended questionnaire in Likert scale allowed the respondents to choose optional agreement choice from "strongly agree" to "strongly disagree" by marking it (Dornyei, 2002, pp. 36-37).

Beside questionnaire, the writers also used interview to collect the data. A qualitative interview occurs when the writer ask one or more participants general, openended questions and record the answers (Creswell, 2012, p. 217). In this study, the writers used semi-structured interviews to allow the participant to talk in some depth, choosing their own words to help the writer develop a real sense of person's understanding of a situation. The writers used interview to make sure and to strengthen their opinion about the use of electronic dictionary in enhancing their vocabulary mastery. The interview itself consisted of 5 questions.

To analyze the questionnaire data, each section of the questionnaire was described by using frequency and percentage tables. In calculating the percentage, the writers used the formula by Hatch and Larazation (1991, p. 136). After calculating the frequency and the percentage, the data were then described 
and evaluated by connecting it with the literature. Last, the writer concluded the result of the questionnaire analysis. Conversely, in analyzing the interview data, the writers used some components of the data analysis. Those are data reduction, data display, and conclusion drawing. Data reduction is used to verify the important and the less important data. It is the important component of analyzing the data because the less important data will reduce the validity of the findings. The other component is data display. Data display is used to interpret the data gathered. The data from the interview can be displayed with words. the data were then described and evaluated by connecting it with the literature. Last, the writer concluded the result of the interview analysis.

\section{RESULTS AND DISCUSSION}

In this part, the data from questionnaire and interview were analyzed to answer the research questions. The questionnaire consisted of 7 statements and the interview consisted of 5. The first research question focused on low achievement students' perceptions on engaging electronic dictionary in enhancing their vocabulary mastery. The result from questionnaire showed that the first statement showed 2 respondents or $14.29 \%$ answered strongly agree that they motivated to learn English by using Google Translate. The second agreement chosen by the respondents was the agreement of agree. It shown by 5 respondents or $35.71 \%$ answered agree that they motivated to learn English by using Google Translate. The third agreement chosen by the respondents was the agreement of neutral with 6 respondents or $42.86 \%$ answered neither agree nor agree with the first statement. The last agreement chosen by 1 or $7.14 \%$ respondent was the agreement of disagree that they motivated to learn English by using Google Translate.

The second statement showed 5 or $35.71 \%$ respondents answered agreement that they strongly agree got more English vocabularies through the use of Google
Translate. The second agreement chosen by the respondents was the agreement of agree. It shown by 8 or $57.15 \%$ respondents chose this item. The third agreement chosen by the respondents was the agreement of neutral with 1 or $7.14 \%$ respondent chose it. The third statement showed that 2 or $14.29 \%$ respondents chose the first item "Strongly Agree", 7 or $50 \%$ respondents of them chose the second item "Agree", and 5 or $35.71 \%$ respondents also gave "Neutral" that Google Translate improved their vocabulary mastery.

The fourth statement showed 4 or $28.57 \%$ respondents answered agreement of strongly agree that Google Translate make them easier in mastering English vocabulary. The second agreement chosen by the respondents was the agreement of agree. It shown by 5 or $35.71 \%$ respondents chose this item. The third agreement of neutral, 3 or $21.43 \%$ respondents answered neither agree nor disagree that the use of Google Translate makes them mastered English vocabulary easier. The last agreement chosen by 1 or $7.14 \%$ respondent was the agreement of disagree that the use of Google Translate make them mastered English vocabulary easier.

The fifth statment showed 6 or $42.86 \%$ repondents expressed on the agreement that they strongly agree about the statement number 5 . The second agreement chosen by the respondent was the agreement of agree. It shown by 8 or $57.14 \%$ repondents chose this item. The sixth statement showed 8 or $57.14 \%$ repondents answered agreement of strongly agree, and 6 or $42.86 \%$ respondents chose this item. The last statement showed that 5 or $35.71 \%$ repondents expressed on the agreement that they strongly agree about the statement number 5. The second agreement chosen by the respondent was the agreement of agree. It shown by 7 or $50 \%$ repondents chose this item. The third, item of neutral with 2 or $14.29 \%$ repondents chose this item, it means that they are neither agree nor disagree Google Translate can replace Paper Dictionary. 
From the percentage data, it can be said that the low achievement students have postive perception on the use of Google Translate as a learning tool. Most of them agreed that the use of Google Translate helped them in improving their English vocabulary mastery because Google Translate is easy to use and fast in translating meaning of words. Besides, they also agreed that Google translate can replace Paper Dictionary.

In addition, the writers also used interview to strengthen the data from questionnaire which involved 6 students; 3 students as low achievement students and 3 students as the high achievement students. The data from the first question "Does the use of Google Translate allow you to master the English vocabulary easier? Give your reason!". It showed that low achievement students got more English vocabulary because Google Translate provided bilingual dictionary which help them to translate words in English to Bahasa, so it makes them easier in mastering English vocabulary.

From the second question "Why do you chose Google Translate ?". It showed that low achievement students used Google Translate because they can translate not only one words, but they can translate one sentence all at once. Google Translate also provides immediate access in translating words or sentences and easy to use. From the third question "What are the problems that you usually found while using Google Translate in the learning process?". It showed that they got some problems, such as bad internet connection which affected the performance of Google Translate in translating words. Besides, sometimes the translation in Google Translate is not appropriate. Thus, it makes them to find appropriate words in other sources.

The data from fourth question "If yes, how do you overcome the difficulties?" The data showed that they overcome the problems by asking their teacher if there is a mistake in grammar or in translating the meaning of the words. Besides, they sometimes look for it by using other sources, such as offline dictionary or paper dictionary. Moreover, the data from the last question "In your opinion, can Google Translate replace the Paper Dictionary?" showed that the low achievement students agreed that Google Translate can replace the Paper Dictionary because the use of Google Translate is very easy and provides immediate access in translating words or sentences. Furthermore, they still need other sources to cover the shortcomings of Google Translate.

The second research question focused on high achievement students' perception on engaging electronic dictionary in enhancing their vocabulary mastery. The results from the questionnaire found that the first statement showed that 3 or $18.75 \%$ repondents answered agreement of strongly agree. The second agreement chosen by the respondents was the agreement of agree. It shown by 7 or $43.75 \%$ repondents chose this item. The third agreement of neutral, 4 or $25 \%$ repondents answered neither agree nor disagree that they are motivated in learning English by using of Google Translate. The last agreement chosen by 2 or $12.5 \%$ respondent was the agreement of disagree.

The second statement showed 4 or $25 \%$ respondents chose the first item "Strongly Agree", 10 or $62.5 \%$ respondents chose the second item "Agree", and 2 or $12.5 \%$ respondents also gave "Neutral" that they got more English vocabulary by using Google Translate. The third statement showed that 5 respondents or $31.25 \%$ chose the first item "Strongly Agree", 6 or $37.5 \%$ of them chose the second item "Agree", and 5 or $31.25 \%$ respondents also gave "Neutral" that Google Translate can improve their vocabulary mastery. The fourth statement showed 5 respondents or $31.25 \%$ answered agreement of strongly agree that Google Translate make them easier in mastering English vocabulary. The second agreement chosen by the respondents was the agreement of agree. It shown by 7 respondents or $43.75 \%$ chose this item. The third agreement of neutral, 4 respondents or $25 \%$ answered neither agree nor disagree 
that the use of Google Translate make them mastered English vocabulary easier.

The fifth statement showed 9 or $42.86 \%$ respondents expressed on the agreement that they strongly agree about the statement above. The second agreement chosen by the respondent was the agreement of agree. It shown by 7 or $57.14 \%$ respondents chose this item. In brief, most of the low achievement students agree to the statement above. The sixth statement showed 10 or $62.5 \%$ respondents answered agreement of strongly agree, and 6 respondents or $37.5 \%$ respondents chose the agreement of agree. The last statement showed that 8 or $35.71 \%$ respondents expressed on the agreement that they strongly agree about the statement number 5 . The second agreement chosen by the respondent was the agreement of agree. It shown by 6 or $37.5 \%$ chose this item. The third agreement of neutral with 2 respondents or $12.5 \%$ neither agree nor disagree that Google Translate can replace Paper Dictionary.

Based on the percentage data, the writer concluded that both low achievement students and high achievement students have postive responds on the use of Google Translate. They chose the Google Translate because Google Translate was easy to use and provided immediate access in translating words or sentences. It helped the students in learning English, especially in mastering English vocabulary.

In order to strengthen the questionnaire data from high achievement students, the writers also conducted an interview in English and Indonesias to answer the second research question. This interview involved 3 high achievement students. The data from the first question "Does the use of Google Translate allow you to master the English vocabulary easier? Give your reason!" showed that high achievement students gave positive perception on the use of Google Translate. It makes them easier in mastering English vocabulary because the use of Google Translate is very easy and faster in translating words. Besides, they should not search the words one by one because in
Google Translate they just wrote down the words that they want to translate.

From the second question "Why do you chose Google Translate?". It showed that high achievement students used Google Translate because it can translate not only words but also sentences. They do not need to search the words one by one, but they just write down what words that they want to translate. Furthermore, the Google Translate is free and it can be accessed by using their smartphones. That is the reason why they chose Google Translate.

From the third question "What are the problems that you usually faced while using Google Translate in the learning process?" showed that they got some problems like bad internet connection that affected the translating process and the translation in Google Translate is not always correct. The data from fourth question "If yes, how do you overcome the difficulties?" showed that they overcome the problems by asking their teacher if there is a mistake in grammar or in translating the meaning of the words. Besides, they sometimes look for it by using other sources such as offline dictionary or paper dictionary to make sure the translation. The data from the last question "In your opinion, can Google Translate replace the Paper Dictionary?" showed that the high achievement students agreed that Google Translate can replace the Paper Dictionary because the use of Google Translate is very easy, more simple and provides immediate access in translating words or sentences. Meanwhile, they still need another sources to cover the shortcomings of Google Translate in translating words.

In addition, the result from the interview showed that there were not significant differences regarding the perception between the low achievement students and high achievement students. Both of them had positive perception about electronic dictionary especially the use of Google Translate. They agreed that the use of Google Translate could improve their vocabulary mastery because Google Translate is easy to use and provides 
immediate access in tranlsating words or sentences. They just wrote down the words or sentences that they want to translate as simple as that.

Nevertheless, the writer also found that there were some problems in using Google Translate. Based on the interview data from the third question "What are the problems that you usually find while using Google Translate in the learning process?" showed that bad internet connection is one of the problems that are usually found while usinng Google Tranlate. It affected the performance of Google Translate in translating words or sentences slower. Besides, sometimes the translation in Google Translate is not always correct. Yet, they could overcome it by asking their English teacher, and found out the answer from other sources such as offline dictionary or paper dictionary.

The writer believes that from the finding, using electronic dictionary makes both low and high achievement students improve their English vocabulary mastery because of the advantages of electronic dictionary especially Google Translate that is easy to use and fast in translating words and sentences. Besides, they got more English vocabulary by using this kind of dictionary. Nevertheless, there are some problems while using Google Translate for examples bad internet connection and the translation in Google Translate which is not always correct. Yet, they can overcome it by asking their English teacher or they open other sources.

\section{CONCLUSION}

Based on analysis, it can be concluded that there is a same perception between low and high achievement students on the use of electronic dictionary, especially Google Translate. Most of them agreed that the use of Google Translate helped them in improving their English vocabulary mastery because Google Translate is easy to use and fast in translating meaning of words. Besides, there are some problems faced by the students while using electronic dictionary. Google Translate is one of the online dictionary and it has to be connected to good internet connection. Here, bad internet connection affected the performance of Google Translate which then makes the Google Translate translate the words slower. Moreover, the Google Translate is not always correct in translating words or sentences and it also has a problem in grammar. Yet, they can overcome the problems by asking their English teacher or they tried to find the answer from other sources, such as paper dictionary and offline dictionary.

Finally, due to the weakness of this study, the writer just investigating the students' perception on the use of electronic dictionary in enhancing students' vocabulary mastery, not in another subject. Thus, it is recommended for other researchers to conduct better research in term of using various instruments, sample, and data.

\section{REFERENCES}

Cameron, L. (2001). Teaching languages to young learners. Cambridge: Cambridge University Press.

Creswell, W, J. (2012). Educational research planning, conducting, and evaluating quantitative and qualitative research (4th ed.). London: Pearson Education.

Dornyei, Z. (2003). Questionnaires in second language construction, administration, and processing. London: Lawrence Erlbaum Associates.

Fink, A. (2003). The survey handbook (2nd ed.). Sage: Sage Publication Inc.

Hatch, E., \& Lazaraton, A. (1991). The research manual design and statistics for applied linguistics. Boston: Heinle \& Heinle Pub.

Murnani, Z. T., \& Salehi, H. (2015). Effect of electronic dictionary as an ICT tool. English Collocation Learning of EFL Learners, 3(5), 366-373.

Rezaei, M., \& Davoudi, M. (2016). The influence of electronic dictionaries on vocabulary. Knowledge Extension, 5(3), 139-148. doi: 10.5539/jel.v5n3p139.

Robbins, P, S., \& Judge, A, T. (2013). Organizational behavior (15th ed.). London: Pearson Education.

Thornbury, S. (2002). How to teach vocabulary. London: Pearson Education. 
Gilang Nugraha, Ratnawati, \& AM. Surachmat

Exploring low and high students' perception on engaging e-dictionary in mastering vocabulary: Cross-sectional survey 